and one in Australia with a membership of 550. In this short note it is impossible to analyse all the naturalist sciences, but since zoology is by far the most populous, it may be taken as illustrating the general trend. Of the $\mathbf{3 4}$ great zoological societies in the world, 13 concern themselves with zoology in general $(40,178$ members), the others are specialist : 10 societies of entomology, with 10,165 members; 7 of ornithology, 10,672; 2 of mammalogy, 1775 ; one of ichthyology, 650 ; and one of ecology, 600 .

THE distribution of the zoological societies gives a glimpse of the Nature-loving character of nations. The United States possesses 12 zoological societies $(15,299)$, Great Britain 7 (19,163), Germany $5(6110)$, Holland 2 (7640), France 2 (2400), one each in Belgium, Canada, Hungary, Austria, Australia, and Japan, with membership varying from 10,415 in Belgium to 538 in Japan. The Belgian Société royale de Zoologie d'Anvers is the largest of zoological societies, its 10,415 members indicating perhaps the standard of the simple acquirements which admission demands ; next on the list in magnitude are two wellknown British institutions-the Zoological Society of London (8200) and the Royal Society for the Protection of Birds (4500). It is curious that zoological societies as things apart did not come into existence until the second quarter of the nineteenth century : Zoological Society of London, 1826 ; Royal Zoological Society of Ireland, 1832 ; Entomological Society of France, 1832 ; Entomological Society of London, 1833 ; Zoological Society of Amsterdam, 1838 ; and so on. Four societies of general natural science hail from the eighteenth century-the Society of Natural Sciences of Danzig, 1743 ; the Society of Natural Sciences of Zurich, 1746 ; the Linnean Society of London, 1785 ; and the Society of Natural History of Hanover, 1797. In all, it would appear that at least 295,617 individuals in the world have an interest, more than fleeting, in the natural sciences.

\section{Leonhard Stejneger, Antiquarian and Naturalist}

IT is fitting that the autumn number (No. 3; 1931) of Copeia, a journal of cold-blooded vertebrates published by the American Society of Ichthyologists and Herpetologists, should have appeared as a special tribute to Leonhard Stejneger and his work. For Stejneger is to American cold-blooded vertebrates what G. A. Boulenger is on this side of the Atlantic. Endowed with great personal charm and a willingness to share his profound knowledge, to which the writer of this note has more than once been indebted, Stejneger is a man in whom great diversity of interests and talents has been combined. As Thomas Barbour in a tribute to his friend says, "Being an antiquarian, a classicist, a rarely accomplished linguist, and a naturalist in the widest sense, he possessed a foundation on which with good health and great industry he has built a mighty structure of rarely excellent work". The anniversary number, with its many papers on reptiles, amphibians, and fishes, is a fitting monument to this native of Bergen and graduate of the University of Christiania, who since 1882 has been associated with the Smithsonian Institution and since 1911 has been its head curator of biology.

\section{Reindeer Ranching in Northern Canada}

Domestic reindeer were introduced into Alaska from Siberia at the end of the last century and have done so well there, according to Mr. M. A. Earle Kelly in an article in the National Review for February (p. 215), that the reindeer ranching industry in Alaska is expected to become more important than mining. Now, he says, the three-year trek of Canada's first herd, of 3000 , is nearly at an end, as they will shortly arrive at the Mackenzie delta, there to furnish stock to be established across northern Canada in the interest of the Eskimo, hard-pressed by contact with civilisation, which has destroyed or driven away the animals on which he lived. It is hoped that he will become a reindeer rancher, and four families of the Lapps, so well known in this capacity, have already reached Kittigazuitt in the Mackenzie estuary, in company with Mr. A. E. Porsild, who, with his brother, has been arranging for the purchase and transport of the herd for the Canadian Government. Reindeer have done so exceedingly well in Alaska, which is now even supplying their meat for American markets, that there should be no obstacle to similar success in the contiguous Canadian tundra, which, it is estimated, could carry $12,000,000$ of them, where ordinary domestic ungulates could not live.

\section{The Cigarette Habit}

Aт a meeting of the Society for the Study of Inebriety and Drug Addiction on April 12, a paper on the cigarette habit was read by Dr. J. D. Rolleston, who dealt with its history, economics, pharmacology, and clinical aspects. Cigarette smoking appears to have originated in South America, where it was reported by travellers and missionaries in the eighteenth century, and thence to have been introduced to Spain, where it was described by Casanova in a visit to Madrid in 1767. The cigarette was afterwards introduced into France and Italy, but it was not until after the Crimean war (1856), when French and English officers acquired it from their Turkish allies, that the cigarette habit became diffused over Europe. Germany, where the cigar was more popular, was among the last European countries to adopt the cigarette; it did not become firmly established in England until the 'eighties. There has been a great increase of cigarette smoking since the War, especially among women, in all European countries and the United States. Dr. Rolleston pointed out that the cigarette differs from other preparations of tobacco in its nicotine content being lower than that of the cigar or pipe, whereas the amount of carbon monoxide in cigarette smoke is comparatively high. Furfurol, which is usually absent in the smoke of the pipe and cigar and present in only very small amounts in that of the Turkish cigarette, is found in comparatively large quantities in the smoke of the cheaper kinds of Virginia cigarettes and is liable to give rise to symptoms of intoxication. Medical opinion is still divided as to the part played by tobacco in general and the cigarette in particular in the causation of

No. 3260, VoL. 129] 
certain diseases, such as angina pectoris and cancer in various situations, and the risk of laryngeal involvement in smoking by tuberculous patients. General unanimity, however, seems to prevail as to the injurious effects of smoking by the young or by the subjects of cardiac neurosis or peptic ulcer.

\section{Food Preservation by Refrigeration}

THE publication, by the Australian Council for Scientific and Industrial Research, of a survey and scheme for research in refrigeration as applied to the preservation and transport of foodstuffs is a matter of importance at a time when attention is being focused on means of improving and extending export trade. The report has been prepared by Dr. J. R. Vickery, who is in charge of the newly created Section of Food Preservation. Information is particularly required as to the possibility of exporting beef in a chilled rather than frozen condition, and since there appears a considerable outlet in Great Britain for Australian bacon pigs, and good ham and bacon can be manufactured from frozen carcases, investigations are needed to determine the best methods of freezing, storing, and thawing them so that the curing process may be most successfully carried out. Fruit, particularly apples and pears, forms another large branch of Australia's export trade, but much loss is sustained annually through wastage during transport. Besides the need for more definite information as to the best type of storage conditions, knowledge is lacking as to where temperature and humidity are particularly important, and how far pre-picking factors such as orchard conditions and degree of maturity of the fruit, etc., may affect its subsequent storage life. The report concludes with recommendations for the establishment of two laboratories with attached cold storage facilities, at Brisbane and Melbourne, the former to study problems in meat export trade and in the transport of tropical fruits, and the latter to investigate the preservation and transport of non-tropical fruits.

\section{Estimation of Food in a Bird's Stomach}

THREe methods have been employed in estimating the quantity of food in a bird's stomach, in order to discover whether a bird is beneficial or harmful: the materials found may be weighed; they may be measured by volume; they may be counted. The weighing method is not practicable, because quantities are sometimes exceedingly small, and besides, relative weights of vegetable and insect matter convey no real information about the economic status of the bird. The second method, of estimating by volume beneficiál insects and injurious insects, useful vegetation and useless vegetation, has been almost universally adopted, following the practice of the experts in the Bureau of the Biological Survey of the United States Department of Agriculture. A reaction from this method is noticeable in a monograph on the foodhabits of the Californian brewer and red-winged blackbirds by Pablo S. Soriano (California Fish and Game, 1931 , p. 361). Here percentage by volume has been used only in estimating the space occupied by vege- table food or animal food or pebbles in the stomach, since the presence of one limits the presence of the others. But, since the degree of injury or benefit that an animal does depends directly upon the total number of injurious organisms that it destroys, the numerical method, of actually counting the specimens, has been followed in taking the percentage of the different kinds of foods. So an old method, once universally used, but ousted by the volumetric method, returns to favour again.

\section{Advancement of Science in Australasia}

THE twenty-first meeting of the Australian and New Zealand Association for the Advancement of Science is to be held in Sydney, during the week commencing Aug. 17. The president is Mr. E. C. Andrews, Government Geologist, Sydney, and the president-elect Sir Hubert Murray, LieutenantGovernor of Papua. According to the preliminary programme, the following presidents of sections have been appointed: Section A (Astronomy, Mathematics, and Physics), Prof. C. E. Weatherburn, University, Perth; Section B (Chemistry), Prof. L. S. Bagster, University, Brisbane; Section C (Geology), Prof. H. St. J. Summers, University, Melbourne; Section D (Zoology), Prof. G. E. Nicholls, University, Perth; Section F (Anthropology), Mr. E. W. P. Chinnery, Government Anthropologist, Rabaul, Mandated Territory of New Guinea ; Section G (Economics, Statistics, and Social Science), Mr. E. C. Dyason, 92 Queen Street, Melbourne; Section H (Engineering and Architecture), Mr. J. R. Kemp, Main Roads Commission, Brisbane ; Section I (Medical Science and National Health), Dr. R. W. Cilento, Director of Tropical Hygiene, Brisbane; Section K (Agriculture and Forestry), Prof. J. W. Paterson, University, Perth; Section L (Veterinary Science), Dr. W. A. Robertson, Director of the Division of Veterinary Hygiene, Department of Health, Canberra, F.C.T.; Section M (Botany), Dr. R. S. Rogers, 118 Hutt Street, Adelaide; Section $\mathrm{N}$ (Physiology and Experimental Biology), Dr. C. H. Kellaway, Director of the Walter and Eliza Hall Institute, Melbourne Hospital, Melbourne; Section P (Geography and Oceanography), Dr. P. Marshall, Department of Scientific and Industrial Research, Wellington, New Zealand. The honorary general secretary of the Association is Dr. A. B. Walkom, Science House, Sydney.

\section{$\mathrm{X}$-Ray Crystal Analysis and its Applications}

The discourse to be given by Sir William Bragg at the Royal Institution Conversazione on Friday evening, May 6, will be related to the various developments in pure and applied science which have depended on the use of the X-ray methods of analysing crystal structure. In order to supplement the discourse, which cannot refer to more than a few of the more important points, an exhibition is being arranged in the rooms of the Royal Institution which will demonstrate more fully the work that has been done. The contributors will be those who have carried on research work in this subject in various British labora- 